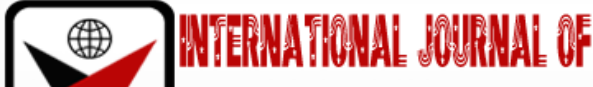 X
}

ISSN 2278-0211 (Online)

\section{Plasma Lipid Peroxidation and Autohaemolysis Status in Sicklers, Carriers and Normal Individuals}

\author{
Arinze Uche Winifred \\ Lecturer, Department of Biochemistry, University of Nigeria, Nigeria \\ Alumanah Edwin 0. \\ Professor, Department of Biochemistry, University of Nigeria, Nigeria
}

\begin{abstract}
:
Sickle erythrocytes and their membranes are susceptible to endogenous free radical mediated oxidative damage which correlates with the proportion of irreversible sickle cell. Measurement of spontaneous lysis (Autohaemolysis) of redcells in sterile defibrinated blood after 24 or more hours of incubation at body temperature $\left(37^{\circ} \mathrm{C}\right)$ were found useful in the investigation of certain hemolytic status.Blood samples from normal haemoglobin genotype, homozygotes (HbAANormal), sickle heterozygotes(Hb AS- Carrier) and sickle homozygotes (HbSS- Sickler) of agesbetween 20 and 30 years collectedfrom the University of Nigeria TeachingHospital (UNTH) Enugu,were used for this study. The Autohaemolysis of the red blood cells of the different haemoglobingenotypes was estimated after incubation for 24 hours at $37^{\circ} \mathrm{C}$. Lipid peroxidation estimation was also carried out in all the subjects blood samples. The result of Autohaemolysis estimation showed a mean value of $4.6 \pm 0.50,6.5 \pm 0.20$ and $8.1 \pm 0.21$ for haemoglobin genotype AA, haemoglobingenotype 'AS'and haemoglobin genotype 'SS' individual respectively. Thehaemolysis observed in sickle haemoglobin was significantly higher $(\mathrm{P}<0.05)$ than that of carriers and normal individuals.The result of the lipid peroxidatin estimation (expressed as concentrationof malondialdehyde (MDA) in ug/L) showed mean value of $0.78 \pm 0.06,1.25 \pm 0.17$ and $1.55 \pm 0.29$ for Haemoglobin genotype 'AA', Haemoglobin genotype 'AS' and Haemoglobin genotype 'SS' respectively. The lipid peroxidation observed in sicklers was significantly $(\mathrm{P}<0.05)$ higher thanthat of carriers and normal individuals. This study showed that both the Autohaemolysis and Lipid peroxidation product estimated wassignificantly $(\mathrm{P}<0.05)$ higherinsickle haemoglobin which is in agreement with previous studies done by other researchers.Sicklecellsare prone to spontaneous lysis(autohaemolysis).Conclusively sickle erythrocytes and theirmembrane are susceptible to endogenousfree radical mediated oxidative damagewhich correlateswith the proportion of irreversibly sickled cell.Therefore, peroxidation of membrane may be a possible mechanism of red cell membrane damage in sickle cell patients relative to normal individuals.
\end{abstract}

Keywords: Lipid peroxidation, Autohaemolysis, Sickle cell, Malondialdehyde, Haemoglobin, Membrane, erythrocytes.

\section{Introduction}

Decades ago, peroxidation was only known in the chemistry of oils and fats,rancidity and its interest were mainlyconfirmed to the field of food technology. The possibleimportance of lipid peroxidation in biology as a damaging process for cellular membranes was first suggested by the studiestappel [i]. lipid peroxidation is one of the reactions set in motion as a consequence of the formation of free radicals in cells and tissues ( $\{2\}-\mathrm{L} 4]$ ). The membrane of mammalian cellscontain large amounts of polyunsaturated fatty acids (PUFA) which can undergo peroxidative chain reaction with subsequent disruptions of both the Liposomes and cellular membrane, any specie that has sufficient reactivity to abstract a hydrogen atom from a polyunsaturated fatty acid side chain in membrane lipids may initiate this process ([5] - [6]).

Sickle cell disease (SCD) is a blood disorder caused by mutation in thehaemoglobin chain, whereby the $6^{\text {th }}$ isamino acid (glutamic acid) isreplaced by valine.This mutation lead to deformation of the redblood cell into a sickle cell shape making it inflexible and unable to transverse the capillary beds. [7] - [8] sickle erythrocytes and their membrane are susceptible to endogenous free radical mediated oxidative damage which correlates with the proportion of irreversibly sickled cells [9].The (sicklegene) S-gene dosage increases from zero in normal individualsto one in carriers and two in sicklers when consequently increase plasmamalodialdehyde. [9]- [11].

Measurement of spontaneous lysis (autohaemolysis of red cells is useful in the investigation of certain haemolytic status. 
This study is aimed among other thingsto investigate the correlation between lipid peroxidation and the proportion of irreversibly sickled cells in the haemoglobin genotype 'SS'.This study also investigates the autohaemolysis status of sicklers in relation to carriers and normal individuals, inorder toascertain the correlation betweensickle cell disease and incidence of spontaneous lysis (Autohaemolysis).

\section{Materials and Methods}

\subsection{Materials}

\subsubsection{Blood Samples}

Blood samples from human subjects were used for this study.Individuals (females) between the ages of 20 - 30 years with haemoglobin genotype 'AA' (normal homozygotes), haemoglobin genotype 'As' (sickle heterozygotes) and haemoglobin genotype 'SS' (sickle homozygotes) were used for this study.

5 mililitre $(5 \mathrm{ml})$ of various blood was collected by clean venopuncture from each subject using a plastic syringe with minimum stasis, into commercially prepared concentration of sequentrene- ethylene di-amine tetra-acetic acid(EDTA) bottles.Each sample was mixedgently and thoroughly to ensure anticoagulation.

\subsection{Methods}

\subsubsection{Genotype determination (Dacie and LewisMethod [10]).}

Genotypes were determined using cellulose acetate electrophoresis for separation of haemoglobin.

Principle:haemoglobin when placed in an electric field will migrate to one of the electrodes. The difference in charge distribution and molecular weight of haemoglobin at different PH values is used in the separation of the haemoglobin.

\subsubsection{Estimation Of Autohaemolysis (Jager, Method [II]}

This involves the spontaneous haemolysis developing in blood samples incubated at $37^{\circ} \mathrm{C}$ for 24 hours. The method is based on a measurement of absorbance at $540 \mathrm{~mm}$ due to exoerythrocytic haemoglobin supplied to the medium by spontaneous lysis of erythrocyte membranes and affected by peroxide oxidation of lipids with atmospheric oxygen.

Calculation was carried out using theequation

$$
\mathrm{X}=\frac{\left(E_{1}+E_{2}\right) 100}{2 E_{3}}
$$

Where $\mathrm{X}=$ Degree of autohaemolysis $\mathrm{E}_{1}$ and $\mathrm{E}_{2}=$ the absorbance measured for the first and the second sample respectively. $\mathrm{E}_{3}=$ the absorbance measured for the third sample (distilled water).

\subsubsection{Estimation of Lipid peroxidatin(Wallin et al method,)[12]}

The lipid peroxidation was estimated using Albro et al method.

Principle Thiobarbituric acid reacting substances (in this case, malondialdehyde) reactwith thiobarbituric acid to give a red or pinkcolor which absorbs maximally at532 $\mathrm{nm}$.

\subsubsection{Preparation of Lipid Peroxidation Standard Curve (Albro, etal, 1986 method[13])}

The Lipid peroxidation Standard curve was prepared using Albro et al method. The standardcurve was used to estimate the amount of Malondialdehyde (MDA) released in the samples.

\subsection{Data Analysis}

Data were analysed with computer using the SPSS version 7.5 softwarepackage. Mean values (SD) experiments withduplicate samplings were taken for each analysis.Differences between groups were assessed by one-wayAnova while differences within groups were assessed by student t-test. The acceptance level of significancewas $\mathrm{P}<0.05$.

\section{Result and Discussion}

\subsection{Results}

3.1.1. The result of Autohaemolysis estimation on the HBAA, HbAA and $\mathrm{Hb}$ SSerythrocytes.

Autohaemolysis estimated (Figure I) for Haemoglobin genotype 'SS" (HbSS) showed a significant(P < 0.05) increased when compared with that of haemoglobin genotype 'AA' (HbAA). 


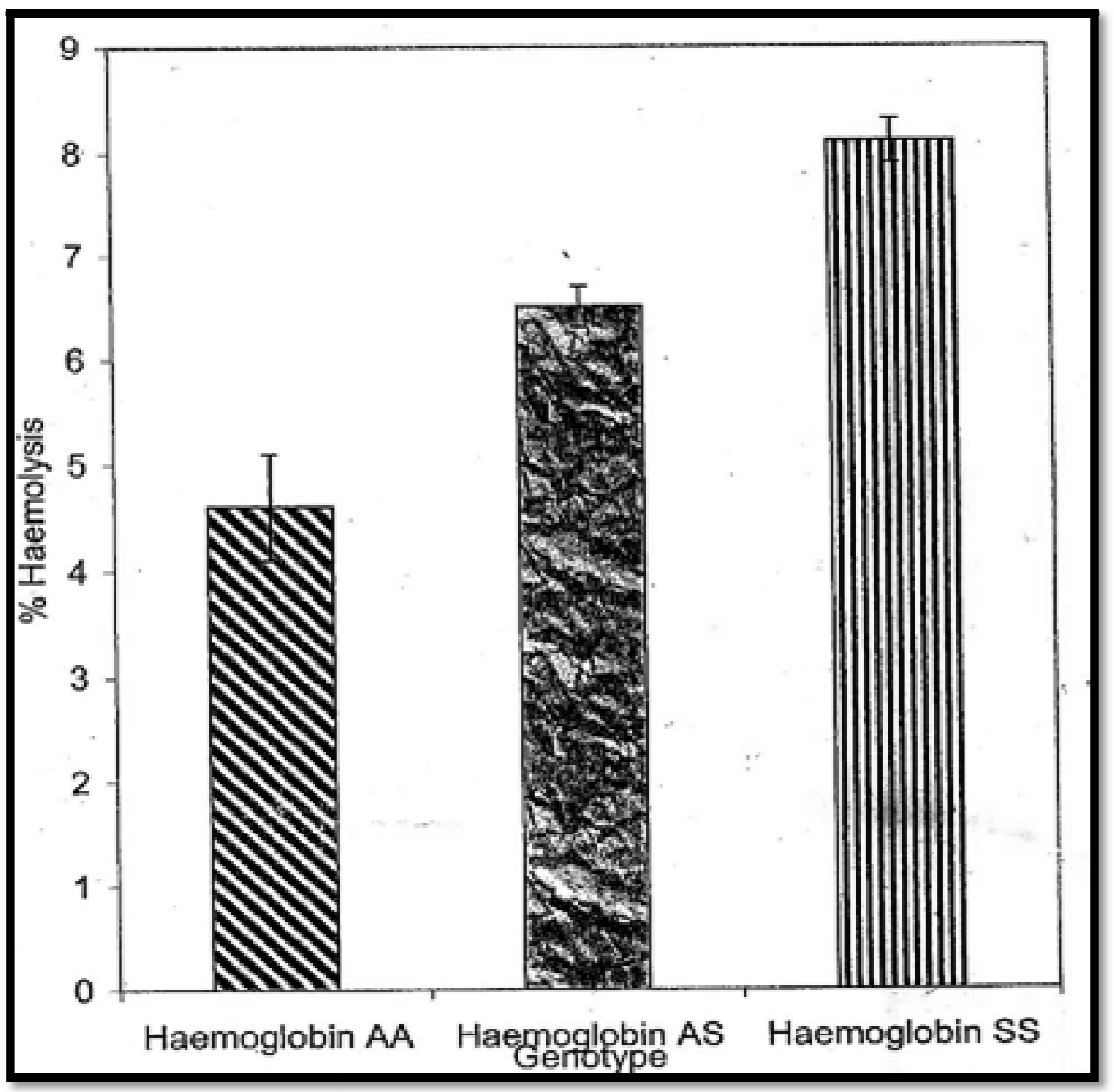

Figure 1: Histogram of the Estimated Autohaemolysis of Hemoglobin Genotypes 'Aa', As and 'Ss' Individuals

The mean value of autohaemolysisestimated for $\mathrm{HbAA}, \mathrm{HbAS}$ and $\mathrm{HbSS}$ was $4.6 \% \pm 0.5,6.5 \% \pm 0.20$ and $8.1 \% \pm 0.21$ respectively (Table I)

\begin{tabular}{|c|c|}
\hline HB genotype & Estimated autohaemolysis (\%) \\
\hline AA & $4.6 \pm 0.50$ \\
\hline AS & $6.5 \pm 0.20$ \\
\hline SS & $8.1 \pm 0.21$ \\
\hline
\end{tabular}

Table 1: Result of autohaemolysis estimated in AA, AS and SS individuals

\subsubsection{Result of Lipid Peroxidationestimate on the HbAA, HbAS and HbSSerythrocytes}

Theestimated amount of malondialdehyde (Lipid peroxidation product) released in the blood samples using malondialdehyde (MDA) Standardcurve (Figure 2) 


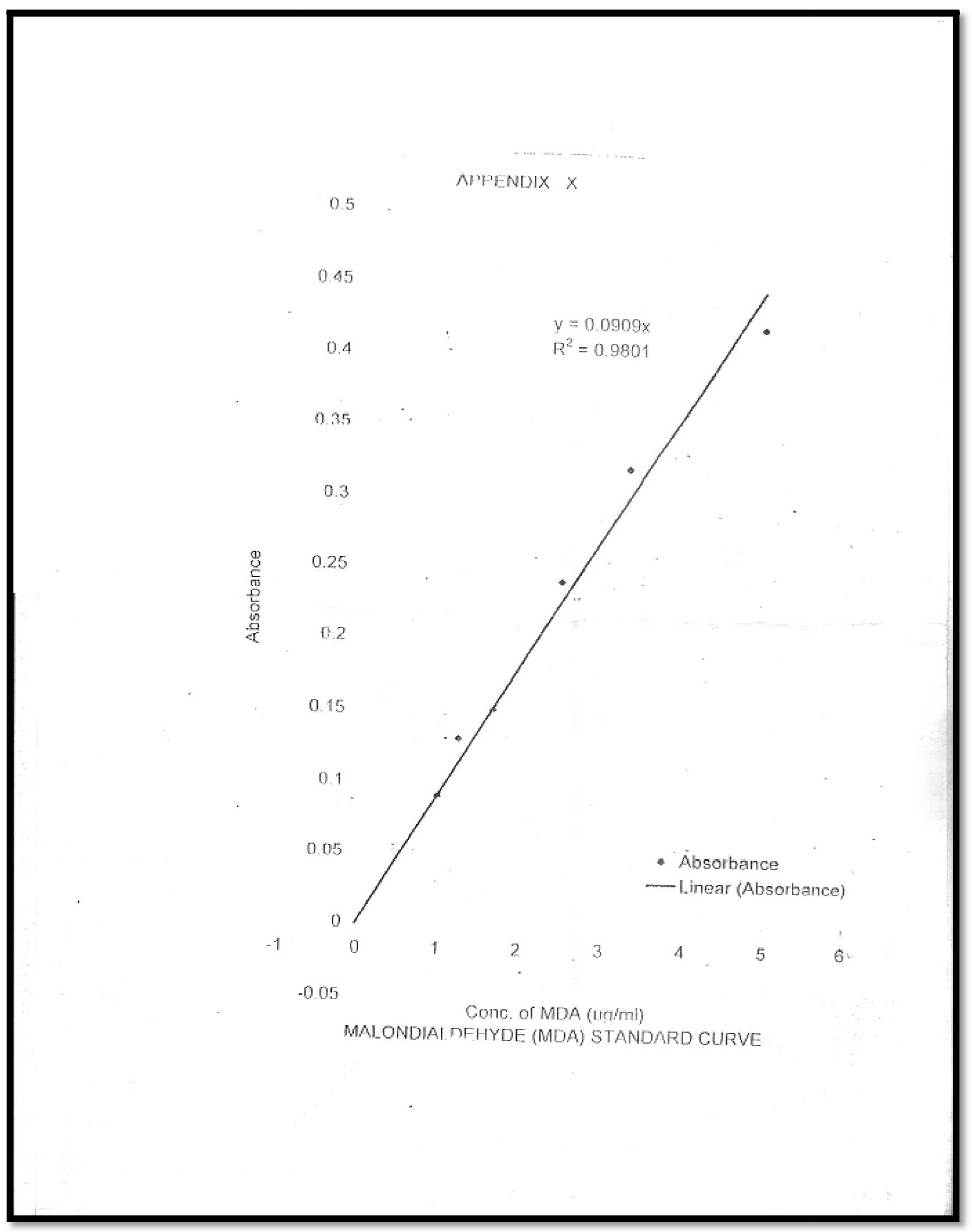

Figure 2

Showed a significant $(\mathrm{P}<0.05)$ increase inhaemoglobin genotype 'SS' (HbSS) individuals when compared to haemoglobin genotype 'AS' (HbAS) and haemoglobingenotype'AA' (HbAA).The mean value of the lipid peroxidationproduct(expressed as concentration of MDAug/l) was $1.55 \pm 0.29,1.25 \pm 0.17$ and $0.78 \pm 0.06$ for HbSS, HbASand $\mathrm{Hb}$ AA individuals respectively(Table 2). 


\begin{tabular}{|c|c|c|}
\hline Genotype & Amount ofmalondialdehyde (MDA) (ug/ml) & Unit \\
\hline AA & $0.78 \pm 0.06$ & (ug/ml) \\
\hline AS & $1.25 \pm 0.17$ & (ug/ml) \\
\hline SS & $1.55 \pm 0.29$ & $\mathrm{ug} / \mathrm{ml})$ \\
\hline
\end{tabular}

Table 2: Result of Lipid Peroxidation Estimated on the AA, AS and SS Individuals

\section{Discussion}

Theresult of the autohaemolysis estimated on the haemoglobin genotype 'SS' (HbSS) was significantly $(\mathrm{P}<0.05)$ increased when compared with the autohaemolysis estimates for haemoglogin genotype'AS'and haemoglobin genotype 'AA'individuals. Thisobservation is becausethe sickle erythrocytes are more fragile than normal ones. The sickle erythrocytes are thereforemore liable to haemolysis than the normal ones. This result in agreement with earlier studiesdone by some researchers ([14], [7], [9], [16], [17]).

The results of the lipid peroxidation assay for all the haemoglobin genotypes studied showed that malondialdehyde (MDA) concentration in HbSS individuals was significantly $(\mathrm{P}<0.05)$ higher when compared with that determined for HbAS and HbAA individuals.This results in agreement with lipid peroxidation studies done on these haemoglobin genotypesby other researchers ([4], [9], [12], [15],(17) - [19]).

Rapid haemolysis associated with sickle erythrocytes could give rise to precipitation of abnormal deposition of more ferritin-like iron which has been implicated in the enhancement of oxidative stress.Consequently, heightened lipid peroxidation couldhave occurred under enhanced oxidative stress.

Sequel to the fact that excessReactive Oxygen Species (ROS) are generated by 'SS' erythrocytes than normal 'AA' erythrocytes, it is expected that higher oxidation stress could be created and subsequently more lipidperoxidation process will occur in sickle cell subjects than in normal individuals, thereby leading to the generation of higher malondialdehyde (MDA) level (as a product of lipid peroxidation) in HbSS than in HbAS and HbAA individuals as observed in this study.

\section{Conclusion}

Conclusively sickle cells are more prone to spontaneous lysis (autohaemolysis) than the normal cells. Sickle erythrocytes and their membrane are susceptibleto endogenous freeradical mediated oxidative damagewhich correlates with the proportion of irreversibly sickled cells.The sickled cells experience more lipid peroxidation than normalcells.Therefore, peroxidationof membrane may be a possible mechanism of red cell membrane damagein sickle cell patients relative to normal individuals. Measurement of spontaneous lysis (autohaemolyis) of red cells was found useful in the investigation of certain haemolytic status.

\section{References}

i. $\quad$ A.L. "Tappel is infree radicals in Biology" Pyror, W.A (ed) Academia Press, New York 4:21-47 .1980.

ii. $\quad$ H. Sies “Oxidative Stress”. Academic Press, London. Pp 34-45 .1985

iii. B. Halliwell B. and J.M.C. Gutteridge. "Free Radicals in Biology and Medicine" 2nd Edition, Clarendon Press, Oxford. Pp 22 - 24. 1989

iv. M. Comporti. "Lipid Peroxidation. An overview in: Free Radicalfrom Basic Science to "Medicinal" Poli, E. Albani and M.U Dianzani (eds) Birkhaster-Verlag Basel Switzerland Pp 65-79. 1993.

v. $\quad$ S.D. Aust and B.A. Svingen "in Free Radical in Biology" W.A Pyror (ed). Academic Press New York 5:91-113 )1982)

vi. O.I. Aruoma "Experimental Tools in Free Radical Biochemistry. In Free Radical in Tropical Diseases". Harwoad Academic Publishers, USA. Pp. 233-267 (1993)

vii. M.J.A. Tanner and D.J. Anstel “Red cell Membrane disorders” Clin.Haematol 12:605 - 770. (1999).

viii. $\quad$ W.T. Tse and S.E Lux. "Reds Cell Membrane Disorder" Br. J. Haematel 104: 2-13 (1999).

ix. $\quad$ C. Rice-Evans, S.C Omorphos and E. Baysal "sickle Cell Membrane and oxidative damage" Biochem J. 237 (1). Pp. 265 269 Jul., 1986.

x. $\quad$ J.V. Dacie and S.M. Lewis "Practical Haematology" $8^{\text {th }}$ edition Church Living Stone, London. Pp. 215-224. 1999

xi. F.H. Stroev and V.G Makarova (eds). "Quantitative estimation of spontaneous haemolysis in: Manual in Biochemistry. Mir. Publishers, Moscow - Russia. Pp. 248 - 252. 1989.

xii. $\quad$ B. Wallin, B. Rosengren, H.G. Shetzar and G. Camejo. " Lipo protein oxidation and measurement of thiobarbaturic acid reacting substance (TBARS) formation in a single microtive plate: its use for evaluation of antioxidant”. Ann. Biochem. 208:10 - 15. 1993.

xiii. P. W. Albro, J.F. Corbelt and J.7 Schroeder. "Generation of hydrogen peroxide by incidental metal catalysed autoxidation of glutathione J. Org. Chem. 27:Pp191-203. 1986

xiv. $\quad$ R. Wyler. "Malaria resurgence, resistance and research". New Engl. J. Med. 308: Pp 875 -878. 1983.

xv. V.N. Ogugua and M.Os. Eze "Plasma Lipid peroxidation and antioxidant status in sicklers carriers and normal individuals". Nigeria Journal of Biochemistry and Molecular Biology 16 (3); Pp. 152 - 156. 2001

xvi. R.P. Hedlund. "Accelerated autoxidation and heme loss due to instability in sickle haemoglobin" proceeding to the National Academy of Science, USA. 85; 237 - 241. 1988 
xvii. R.P. Hebbel. "The sickle erythrocyte in double jeopardy, Autoxidation and iron decompartmentalization"seminar in Haemotolgy. 27; 51 -69. 1990.

xviii. P.N. Ugoegwu and A.E. Onwurah. "Correlation of lipid peroxidation index with sickle haemoglobin concentration in Malaria positive and negative status of AA, AS and SS individuals from the university of Nigeria, Nsukka Community J. Bio. Res and Biotech. I (i): 97 -114. 2003

xix. R.H. Douglas and W. G. Wood. "Genetic complexity in sickle cell disease. The National Academy of Science of USA. 106 (3); 11595 - 11596. 2008. 